\title{
THE SECURITY CHALLENGES OF EASTERN EUROPE - A THEORETICAL APPROACH AT MACRO LEVEL -
}

\author{
Prof. Dr. Cengiz OKMAN*
}

\section{Preface}

There is no doubt that the costs of the Cold War have been substantial. It inflicted oppressive political regimes on the peoples of Eastern Europe, who were denied basic human rights by their forced membership in the Soviet empire. It consumed national wealth, by giving rise to large and costly defence establishments in both East and West'. This period has lasted for over forty years, and it was not later than the late eighties that the long lasted evolutionary process of cold war politics suddenly began to develop into the stage of revolutionary change on a world wide basis.

Gorbachev's political genius, from a collective learning perspective, was to see through the stalemate of this conventional hegemony - counter hegemony cold war logic and to position himself ideologically on the side of change and of the future (his new thinking), leaving the defence of the old to his oppenents at home and abroad'. Ideologies are born radical, mature in pragmatism, and turn self-righteously inflexible in old age as those who heavily invested in them weigh the psychic at and material costs of change. Gorbachev knew when to cut his losses and how to symbolize the collective learning his people would have to undertake to restructure their economy to complete in the 21st. century. His policies of reform and reluctance to use force, in

- Associale Professor of International Affairs at Department of International Relations and EC Institute of Marmara University

1 Nevertheless, the net human and economic cost of the Cold War order has been far less than the cost of the European order of $1900-45$, with its vast violence and suffering. A cold war order without confrontation would have been preferable to the order that aclually developed, then the peace that the Cold War order produced could have been enjoyed without its attendant costs.

2 The argument underlying the concept of "collective learning" is that the only way that individuals, economic organizations, and states can cope effectively with global economic change (and the information overload it implies) is through a process of collective leaming and structural positioning, which breaks beyond status quo-conditioned maintenance models to initiate targeted, innovative, strategic risk - taking and adaptation. Collective learning in international economics (and also in politics) is made up of three elements: the global organizational environment, national and cultural behavior and cognitive or managerial strategy and policy in the context of exiting political and economic structures. 
turn, stimulated the spontaneous collective learning of the peoples of Eastern Europe, permitting democratic movements from Poland, Hungary, Czechoslovakia, East Germany, Romania, and Bulgaria to position themselves strategically in 1989 for radical political and economic change.

\section{On the realm of definitions:}

Towards the end of the century we are once again facing the task of going back to the concept of security with the aim of redefining it for Eastern Europe under today's rapidly evolving conditions in overall terms. At this stage, from an analytical point of view some aspects deserve special attention to begin with. First of all, the definition has to be determined in a way to serve our purpose; secondly, the level and the scope of the definition has to be formulated in a manner to coincide with our analytical frame; and finally, the evaluations on Eastern Europe have to be accorded with the chosen frame. Each section deserves proper clarification.

A - Concerning the first section, if security is defined as the absence of threat or sense of threat to the fundamental values of a concerned party (e.g., institutions, societies, states etc..) the striking outcome would be an overgeneralization that could be stretched all the way down, for instance, to Kenneth Boulding's abstraction ${ }^{3}$. On the other hand, such definitions would, as the result of their scope and style, highly emphasize the traditional concept of "national interest" and can be utilized by the national security apparatuses in the course of their specific planning procedures. Yet, security in our time is too complex of a notion to be confined into the limited framework of the concept of national interest. It is especially true for Eastern Europe today, since the security in this region is underlined by the host of factors, including the ones directly stemming from the concept of national interest yet extending far beyond them owing to rising importance of the economic and socio - political aspects (and the declining influence of military determinants) of security in the region.

Thus the definition has to be purpose oriented. Yet the term "purpose" itself is not a simple expression of national will or a specific problem to be solved. Rather it stems from (or relates to) the analytical frame we are to chose. The purpose could be related to variety of issues ranging from the internally oriented ones to broad and mostly hypothetical natured issues at global level.

What would be the points that could be taken into consideration in defining se-

3 Security is used in Kenneth Boulding's sense as aiming for "unconditional viability", a party that cannot be absorbed or destroyed as an independent source of decisions; as a kind of ideal of absolute independence, freedom, or sovereignty. See:

Kenneth Boulding's, Conflict and Defense: A General Theory (New York: Harper \& Row, 1963). p.58. 
curity for Eastern Europe, then, will largely depend on the level and scope of the analysis we are to choose in approaching to region.

B - Concerning the second section, then, we are to decide on the analytical frame. Merits of the macro and micro levels of analyses will have to be cross examined at this point; and there can be a lot to say about the security challenges of Eastern Europe depending on the level to be decided. My preference will be on the macro level leaving the space for country analyses to our colleagues. Such a decision would inevitably draw our attention to the environmental premises of the security of Eastern Europe, leaving us with the question of how could the overall structure of the world political environment be defined. This is an essential point since the type of the international system prevailing in a given time would be the source of the security determinants (and of the rules of the game nations are to play) to be imposed upon the related regions, here Eastern Europe. Since the end of the second World War a bipolar order has been a dominant structure in global politics underlying the policy and security patterns of the Eastern European countries within a general framework of the East-West exchange process. Indeed, as it was stated by Rotfeld, "the domestic cries in the early 1980's and the attendant deep internal divisions, for instance in Poland, pertaining to almost all vital problems of the state and nation, were unilized politically as elements in a game of East-West relations played by the United States and some of its NATO allies against the Soviet Union other Eastern European countries ${ }^{\text {nd }}$. If this were the frame, and Poland taken as a case, then the security challenges would place priority on;

"1. strengthening the alliance with the USSR; consolidating the position of an active participant of the Warsaw Treaty and the council for Mutual Economic Assistance (CMEA); utilizing this position for the sovereign and effective resolution of problems of internal development, notably for carrying on the reform process;

2. searching for institutional solutions which would give effect to the prohibition on the use of force and promote the development of peaceful relations;

3. counteracting any attempts at undermining the Yalta-Potsdam order and at destabilizing the situation in Europe; isolating and condemning revisionist tendencies in the FRG;

4. pointing to the threats involved in attempts at Europeanization of the process of German unification and at subordinating Europe's interests to the aspirations of the FRG;

4 Adam Daniel Rolfeld, "The Case of Poland, "in Overcoming Threats To Europe: A New Deal For Confidence And Security, ed. by Sverre Lodgaard and Karl Birnbaum (New York; Oxford University Press, 1987). pp. 115-134 (p. 121). 
5. restoring Poland's position in the all-European process of security and cooperation through active engagement in political dialogue; submitting realistic initiatives which take due account of the interests of the patterns, and so on... ${ }^{n 5}$

Hungary, as another example, followed a similar path to that of Poland as it considered that an approximate military balance of power was the basis for European and global peace and security and that its own security was based on its alliance system ${ }^{6}$. Taken in general, in search of defensive superiority, as it was the case also for the West, unilateralism, dialogue or negotiation processes have been the main paths, which the efforts have mutually been concentrated upon for over forty years in Eastern Europe?

Nevertheless, within less than a decade, the conditions of the security orientation on the premises of the traditional line of rationality have themselves turned out to be the full expression of irrationality in definite terms. This is not an irony but a fact, and the reason is a simple one: Today, under the impact of rapidly evolving conditions it is not possible anymore to define the general characteristics of the international system in terms common to traditional writers of the last generation or more ${ }^{8}$. Rather, careful analyses provide us with the opportunity of putting diagnosis on specific systemic "attributes" that at the final stage enable us to draw some generalizations. Accordingly, it may somehow be possible for us to define international order as the mixture of "balance of power" and a kind of "rapidly altering polar order." This is a type of world order whose characteristics can be summarized with the dominant features as follows:

a. Some general trends will continue to be discernable globally: 1) diffusion of power in the world; 2) absence of a dominant actor (like the USSR) as a central figure characterizing the polarized order, and the relative decline in the ability of the United States (and relatively to a much higher degree of Russia) directly to determine

5 lbid.; p. 131.

6 Tarnas Lovassy, "The Case Of Hungary" in Overcoming Threats To Europe: A New Deal For Confidence And Security, pp. 104-115 (p. 113).

7 Sverre Lodgaard, "A New Deal For Confidence And Security," in Overcoming Threats To Europe, pp. $177-209$ (p. 193).

8 Today, it is possible to diagnose the various peculiarities concerning the structure of the international order that may not easily coincide with any of the well-known models which were worked oul, for instance, by Kaplan in his famous study. See;

Morton A. Kaplan, International Politics: Systerns And Process in Intemational Relations (Chicago: Rand McNally, 1970).

9 The term "attribute" should be conceived in the manner it is explained in Systems Thinking by Fritz and Emery to replacing the terms "factor or piece". See:

Fritz \& Emery, eds., Systerns Thinking (Penguin Books; London 1970).

10 On the usage of the term in its classical conlext see: Morton A. Kaplan, International Politics, chp. 2. 
or even, in some cases, much influence results on particular matters in politics, economics, and even military affairs; 3) growing international economic interdependence coupled with an increase in the applicability as well as the effectiveness of economic muscle as contrasted with sheer military might ${ }^{14}$.

b. Closely relating to above points; 1) an increase in the overall capabilities, in relative terms, of smaller states will be noticeable; advanced military technology and weaponry will become increasingly available to Third World countries, 2) as a result of the relative decline in the controlling and organizing abilities of the actors (traditionally possessed super-power status) these countries will be provided relatively more initiative than the previous decades over the regional issues, and 3) economic factors will continue to gain a much higher importance (than any other type of system theoretically defined or materialized during the previous decades) as the attributes of the regulatory mechanisms of the changing world structure ${ }^{12}$. Accordingly, different factor will be influential in the creation of a new balances and power concentrations and along with the newly rising values such issues as the changing orders of the ex communist states, assaults on drug production, trafficking and finance, environment, financing, energy supply etc. will require and receive increasing attention at the expense of more traditional sphere - of - influence and balance of power matters.

c. In the decade ahead of us, rapidly evolving polar order will impose various alignment and re-alignment process upon the system; e.g. the situations in the Balkans, the Middle East and the Central Asia are the initial signs of this. Such --and similar -- processes will take place under the conditions where the determinants of a balance of power order, especially concerning the conduct of rules relating to bargaining, fighting, power concentrations and the rising influence of international organizations of various types would be operational.

Yet, the type of balance of power will differ from traditionally accepted types (e.g. from Kaplan's designs) not in respect to influence of supra national organizations but also with regard to keeping the existing quantity of the actors at a predetermined manner, in order to prevent proliferation in the number of actors with the aim of the preservation of the existing order. A high rate of proliferation process, accompanied by various types of nationalistic movements, will easily come into existence depending on the development as has been the case, for instance, in the Balkans and in the Central Asia which are still in progress since the beginning of the nineties. for Strategic Planners, "in Strategic Review, Spring 1990, pp. 23-31. (p. 26)

12 As it was stated by etzold, "perhaps the most important consideration amid all this change is the growing role of economic influence - whether based on growth, current account surpluses, role in financial trading and capital movement, or sectoral economic technological advantage."

See: Ibid.; p. 26. 
d. Under such conditions, as stated above, attributes of stability in certain areas will continue to increase whereas the determinants of instability will rise in certain other regions ${ }^{13}$. And, in virtually every region, one and more states will attempt to establish regional hegemony. This will require novel superpower approaches to pursuing interests and exercising influence in most world regions.

As the statements above reveal, the main characteristics of the international order have not so far been sufficient to determine a stable system frame that could explain the rules of the conduct for the states in relatively definite terms; rather, states are still in the process of facing an incomplete transformation in a world with variety of rules. This is the essence of the point revealing the complexity of the process; and this is the reason that forces states to be more careful than ever.

C - In the light of the above characteristics, the security challenges for Eastern Europe (as compared to the ones prevailed till the early nineties) turn out to be composed of different sets of considerations. As the conditions for the type of equilibrium (equilibrium under pressure) that have prevailed in the region for over thirty-five years ceased to exist, most of the security conditions stemming from the nature of the international order have also disappeared, leaving the space primarly to socio economic considerations and placing ethical questions combined with certain border disputes to a secondary degree.

By combining the three aspects of the subject regarding the definition of security, then, it is possible to state that, the security process for Eastern Europe today is the reflection of the national security aspirations of the states in the region, into their environment on a world wide basis. As considerations on the political part, in the manner they pertained to traditional balance of power practices in and outside the region and the military aspects of the global politics began to loose their momentum, the other two main components have gradually become dominant sectors of concern: namely the social and economic structures.

Socio-economic components of the national security apparatuses have turned out to be of a vital importance. The reasons that caused the fall of the socialist bloc can be illuminating on our point:

a. They failed because competition in the international market proved them to be inferior. Since the end of the world War II, the gap between their tradeable goods and Western exports, between their innovation potential and Western technology,

13 Today, the US and the Atlantic line the European area (with the exception of Balkans) is among the regions with the rising stability in general terms whereas the Balkans, the Middle East and the Central Asian are among the regions that can be classified in the second group. 
and between the consumer basket they can provide each individual with and Western per capita - consumption has widened ${ }^{14}$.

b. External factors (including market conditions) are regarded as decisive for falling apart of the Socialist states ${ }^{15}$.

In short, they failed because their opening to the global environment in overall terms has never been organized in a manner to provide their socia-political and economic structures with the opportunity and the proper qualities needed for their constant adjustment and regulatory mechanisms.

Taken through such perspective the security challenges facing Eastern Europe today a) are, and will continue to be environmental oriented, b) will heavily be influenced by the type of the international system to be built, and c) will continue to be dominated primarily by the socio-economic factors in the decade to come.

In the light of arguments passed so far, the underlying concept of security for Eastern Europe in the decade ahead can be defined as an overall and continuous adjustment process to their global environment -- which is desired not to be any type involving power politics and bloc orientation -- with the aim of promoting their socioeconomic well beings, and providing their systems with the proper ways and means of integration with the Western Institutions both in political and socio-psychological aspects.

\section{ON THE SECURITY CHALLENGES : THEORY vs REALITY}

An overall approach to be carried on through our analytical perspective (and the departure from such theoretical premises as explained above) makes it methoclogically irrelevant to deal with individually defined issues as the security challenges facing Eastern European States. It is within such a context that many issues, to be specified within their own respective categories (e.g., such military aspects as the production, standardization and the maintenance of equipment, or various ethical disputes, in some cases, accompanied by the border disputes or identity crises accompanied by the process of restructuring socio-political orders, etc.) turn out to be the side-products of rapidly evolving environmental conditions. If this is accepted as reality, then, a deductive type of reasoning can perfectly serve our purpose in defining the nature of the security conditions for Eastern Europe.

14 Padma Desal, "Soviet Growth Retardation, "American Economic Review, vol. 16, No. 2 (May 1986), pp. 175-180.

15 E. A. Hewett, "Economic Reform in the USSR, Eastern Europe, and China: The politics of Economics, "American Economic Review, vol. 79. No. 2 (May 1989), pp. 16-20. 
At this point, in order to explain the overall nature of the on going process, the broad definition formulated above, requires to be supplemented by further statements. In this, the present crises can be conceived as the full expression of the irregularities, on a region wide basis, in the search of finding some ways of getting out of a vicious circle of the existing stability structure (stability under pressure) which is unacceptable for the maintenance of a steady state under the newly emerging environmental premises ${ }^{16}$.

In this respect, some of the problems (especially the ones evolving into violent disputes) can be regarded as the systemic reactions toward the vacuums created around the region - in some respects at the global level ${ }^{17}$. These are the reactions that, are in reality, turning out to be the disputes ranging from the low level ethical and border questions all way up to high level armed conflicts. The crises in former Yugoslavia, for instance, can be viewed through such perspective; and if we do so, then, the scope and the level of the conflicts can be conceived not just originally as the fundamental issues deeply rooted within the system gradually developing into crisis, but as the outcomes of an overall adjustment process. Such an approach makes a lot of difference in the efforts aimed at finding some solutions to the existing as compared to the approaches emphasizing on taking issues within their individually defined frameworks regarding them as the developments independent from certain external conditions, or assigning such conditions to a relatively much lower level of importance.

The matter of deciding on one of these analytical approaches (naturally each leading to different conceptions) can be simplified by our ability in making distinction - through an analogy, for instance, from military strategy -- between the battle orientation and the overall war (or in broader terms the policy) approach; the developments and their results obtained at tactical level often turn out to be tentative (and often deceiving) in their nature whereas the decisive solution are sought within its essentially different framework of the strategic orientation. We have to decide on the nature and scope of such level in approaching to the new security environment of Eastern Europe.

16 A question can be raised here as to how these systems have been able to maintain a cerlain type of stability so far, and why not in the same manner from now on. The answer, without going into detail in theory, can be explained by the simple fact that reveals open systems (her sociopolitical orders) as the entities possessing their own basic attributes and environmental ones holding a predominant calegory among these. Therefore, the changes in this category inevitably force a differentiation in the positions of others; a repositioning process, which at certain stages form certain irregularities. In our case this is labeled as the period of transition.

17 Even if it can be stated that the problems (especially the ones evolving into armed conflicts) are the outcomes of the weaknesses inherent to the region, the logic to counter such a stand can be developed by irying 10 explain the reasons as 10 why a relatively stable order has been sustained for over 35 years without any armed conflict in the region. What is the main factor (or factors) that can slated as missing today. Has any additional attribule of any type (or types) lately been included into the system. A careful reference to our analytical frame gains its momentum here. 
In referring to our case, it would be very hard for us to face the irregularities in the region by persistently trying to proceed on the level of individual crisis issues, which (in our terms) are tactical in their nature. These issues, in fact, reveal their nature (their essence) in their totality that can be conceived as combined with the overall global conditions, with their globally changing premises.

The important point here lies in the fact that the various types of drastic changes with different scope and magnitudes, suddenly emerging around the region by exposing the concerned states to rapidly growing vacuums in the area in political, economic as well as to socio-psychological terms, to which they have never been prepared to ${ }^{18}$.

Closely coinciding with the above arguments, another proposition could be offered on the premises that some crises facing Eastern Europe today can also be regarded as certain way of expressing their own aspirations some of which even might not have gradually been grown on a rational bases. Yet what counts at the moment is the fact that they do have such expectations today, and they all rising at a time when the traditional sources of the overall pressure upon their structures are being removed and the environment itself is going through a rapid differentiation process. It is such a framework that the problem of adjustment turns out to be forming a new basis for their security concerns.

\section{RELEVANT POINTS ON OPTIONS AND FUTURE PROSPECTS}

Approaches concerning the options and future prospects on the subject can methodologically be abundant both in their nature and scope, each leading to different outcomes in style though not necessarily in essence. In the same manner, our reasoning here, coinciding with the analytical framework (explained above), can naturally be expressed through a perspective suitable to its own logic. The options can be evaluated on such a ground; and the prospects can partially be justified by the type and nature of options they relate to.

18 Taking a child's (another type of organism's) training, through analogy, into consideration we can easily trace his preparation psychologically and physically to his environment under essentially parental guidance supported by the various types of institutions of education and training for a considerable period of time. Then, he gradually opens himself to his environment after a certain age (and certain level of mental and physical preparation), but still under the long distance guidance of his parents and the close involvement of social institutions available still playing their roles required. Thus the child becomes ready to proceed and adjust himself to a new environment. Taken through such a logical perspective, (and referring to another level of system of socio-political in nature) it can be questioned if Eastern European states have ever had the opportunity of proceeding on such a line under any type of internationally -- and locally -- organized guidance within a time framework of the last forty years. The answer, for instance, to the question as to why the crises in the former state of Yugoslav have never developed into their intensive stage in scopia but in unexpecled areas, can be searched through the same logic. 
In this respect, the options open to Eastern European states will very much depend on the nature of the framework into which they would choose to place the bases of their overall policy orientations. Such a framework, then, would very much be globally determined one in its nature. The analysis and the proper diagnosis on the possible nature (its related parameters and the rules of conduct) of the emerging international order should be considered as a primary task for them. A kind of concentric approach ${ }^{19}$ to regional problems, therefore -. starting from overall environmental premises and gradually focusing down to individually defined regional issues - could perfectly suit to such orientation. Deciding on the type of the strategic concentration $^{20}$ (in opening towards the region starting from outside), then becomes a critical issue. It is in such a context that the region-wide strategies for the decade ahead will be subjected to a close analysis.

Since the main task facing the region is essentially an adjustment problem, the various concepts of integration (along with existing and newly emerging international institutions) in their broadest sense should carefully be studied and tried to be materialized. This is not just an expression of a simple foreign policy orientation, rather it is the matter of restructuring the socio-political imperatives of the system under the realities to be imposed upon their system by the rapidly evolving environmental conditions. Looked from the other direction such an environmental (concentric) orientation should not be conceived as detrimental to -- on the contrary be regarded as very much in accord with -- the national security objectives of the concerned states in the region since the rate of adjustment on an acceptable level would definitely increase the potentiality in political (internally and externally) and military directions. This is true since it is a commonly shared view that for the decade ahead, it would be difficult if not possible to be economically weak yet militarily strong, politically influential and sociopsychologically stable ${ }^{21}$. Indeed, "as most people agree that a major factor contributing to the revolution in Eastern Europe in 1980 was the poor performance of socialist economies" "This area, then can be regarded as a departure base for the outward oriented maneuvers. Yet, such a consideration should never create a kind of

19 In the theory of strategy such an approach is expressed as the combination of moves under one and unified objective in a coordinated manner; and the coordinated-concentric moves together form the main coordinants of the fundamental principle of "concentration" in theory. The principle of concentration dictates not necessarily immediate involvements in the area (or areas) where the decision is sought, but maneuvering in the areas (or over the axes), where the final objectives are gradually affected, until the decision is attained at the final stage. Of course there are various types of maneuvering depending on the ways the time, space and the mass are utilized. Evaluations on the overall capabilities as compared to the conditions faced in a given time are taken as the bases in choosing the most suitable concentration style for us.

20 The same as footnote no. 19.

21 Thomas H. Etzold, "The Strategic Environment," p. 28.

22 Barbara Krug, "Blood, Sweat, or Cheating: Politics and Transformation of Socialist Economies in China, and Eastern Europe, "in Studies in Comparative Communism, Vol. XXIV, No. 2, June 1991, pp. 137-150 (p. 137) 
false assumption as to neglecting the other areas. Just the opposite is the case since the orientations on economic grounds would not be based only on the plans relating to one area of vitality but on the plans trying to synthesize the economic political, socio-psychological and military aspects as well. This would be regarded as one way of creating psychological influences required abroad, by utilizing the main national sectors as the means of maneuver.

Primacy of the economic orientation, then, can be regarded as an indirect way of carrying the overall policy objectives of Eastern European countries into international arena; in other words, the underlying reason for Eastern European states in deciding on such a policy line stems from the necessity that dictates the strategy of indirect approach "as a general policy frame for these states ${ }^{23}$ Such a policy orientation would dictate upon Eastern Europe to justify its position within the framework of the present transformation process; and in doing this it will be necessary classifying the present actors globally into certain categories so that an idea with regard to a general plan of action can be developed. Such a stand will be necessary in deciding on the positional values of the other states (just like the situation existing on a billiard game table regarding the changing positions of the balls vis - a - vis each other) by studying their weight in rational terms in the field where the game of politics is played on a world wide basis. This is also necessary in deciding on the proper political maneuvers to be implemented towards other groups in order to create psychological effects required.

One of the studies classify states into five main categories, taking economic structures -and their related exchanges- as primary criteria: ${ }^{24}$

1- OECD Nations: members of the OECD, sometimes referred to as "the rich men's club: the U.S., Japan, West Germany, France, and other members of the European Market (EEC), the Scandinavian countries, Canada, Australia, and New Zeland ${ }^{25}$.

2- Newly industrializing countries (NICs): Spain, Portugal, Greece, Brazil, Hong

23 On the strategy and the related subjects of "indirect approach" see:

Andrei Beafre, "A General Survey of Strategy" in National Security and American Society: Theory Process and Policy, ed., by Frank N. Trager and P.S. Kronenberg (University press of Kansas, Manhattan, 1974), pp. 294-314, also see:

Liddel Hart, Indiract Approach (London: Oxford Press, 1970).

24 Robert A. Isaak, International Political Economy: Managing World Economic Change. (New Jersey; Prentice Hall, Inc., 1991 (p.8).

25 Taking the imperatives of today's international order and it's related rules of the conduct into consideration, the actors in this group will also be influential in their overallforeign policy orientations. Consequently, gaining any type of position in these circles will provide the stales in other groups with the opportunity of adjusting themselves into changing world conditions economically as well as politically. 
Kong, Korea, Taiwan and Singapore (as defined by the OECD). These are the most upwardly mobile of the developing countries.

3- Developing oil-exporting nations: a nonhomogeneous group like the others ranging from Saudi Arabia (with the largest oil reserve in the world) to Nigeria and Venezuela.

4- Non-oil-producing developing nations numbering about 100.

5- "Socialist" nations of the Eastern Bloc: the states in the need of rapidly moving toward market economy models.

It is in the analyses of the regional capabilities on a mutual basis that the conditions for a relative independence or dependence for Eastern Europe could be clarified. The cross - examination of the structural positions (e.g. security structure, the money and credit structure, the knowledge structure, the production structure, the value structure, and the overall international exchange structure ${ }^{26}$ would ensure important criteria for such analyses.

The regional status (mostly to be defined on economic and socio-political grounds), under the light of such criteria, could provide us with the ability to assess the overall regional (then national) capabilities as well as the demands for certain types of integrational policies. As a general policy orientation this is an important option open to Eastern Europe; moreover, such an orientation should not be conceived as confined to functional areas, rather it is to be visualized within a wider framework both in functional and geographic terms.

In geographic terms two areas need to be emphasized as the main axes of concentration: namely the Western European area with its existing institutions and prepheral zone -- the region extending from near proximity all the way up to the Far East -- with certain potentialities to be facilitated. Functional terms, on the other hand, should also be interpreted on wider grounds comprising economic, military and socio-political aspects, though the first aspect relatively in a dominant position.

Awareness on the growing fears about the irregularities concerning the internal and external security of these countries resulting from the vicious circle in which they are captured -- a weak economic basis, a poor standard of living, weak democratic traditions, patterns of behavior and identification, and a high potential for internal and external conflicts -- may (in fact should) naturally lead them to place a high priority to Western European area. This is especially true since modern societies are dependent on international cooperation, whereas the former communist economies in the region have lost even their existing forms of cooperation and integration: and on 
many grounds they do not have any chance to form a new supranational economic context, which would enable them to act autonomously to get out of the situation they are in and to survive under the new conditions of the market economy ${ }^{27}$. In this respect, an overall orientation towards Western Europe, and taking the European Community as the main -- and possibly the only -- organization for intensive cooperation and integration should carefully be assessed. Such an orientation would not necessarily signify any tendency to exclude the options for close cooperation within the region: on the contrary, cooperation and sub-regional integration among the states in the region can be regarded as the basis for the European integration as well as another departure point towards other regions. Region wide integrational tendencies can also be justified on theoretical premises in the sense that the parameters for the new state of equilibrium (to lead, in our terms to internal stability) are partially formed by these type of internally oriented moves. Thus, to some extend, the policy-mix adopted by these countries in transition (consisting mainly of two groups of policy maneuvers; namely the stabilization policies and transition policies) can, from our analytical point of view, be viewed as the orientations aiming at preparing internal conditions required not only for internal stabilization but also for some forms of region wide integration ${ }^{28}$.

Needless to say that under the present conditions, a rapid integration with the E.C. cannot be conceived as a realistic option that can easily be materialized for Eastern Europe. Financial and structural problems being at the top, many other deficiencies pose serious obstacles -- and might continue to do so for a considerable period of time. Nevertheless, if the transformation problem in Eastern Europe can be conceptualized within a wider frame work of the European integration process -- and as the part of long term overall European movement -- then, the Western Europeans may deem it necessary to cooperate with the region towards common objectives. In this respect both sides should assume some responsibilities:

"First and most important, the West could provide structural help along the lines of so-called Marshal plan for Eastern Europe to improve the conditions for creating

27 August Pradetto, "Transformation in Eastern Europe, International Cooperation, and the German position" in Studies in Comparative Communism, Vol. XXV. No. 1, March 1992, pp. 23-30 (pp. 24 25).

28 The efforts - and the related developments - within Eastern European states can be viewed on two different grounds: a) in the course of studies relating to the Iransformation of (and the changes within) these societies in various functional areas, and b) within an analytical frame taking the region in its present stale of equilibrium striving for sub - and - supra regional integrational tendencies and con - centric orientations. The second is our line. As an example to the studies pursued on the first ground see the article: Franz - Lothar Altmann, "Is South - Eastern Europe Making It." in The World Today, June 1993, pp. 112-114. 
new structure of production and reproduction compatible with Western economies and for creating the ground work for a gradual and successive integration into the world markets" ${ }^{129}$.

The particular tendencies and potentialities exhibited by some states -- especially Germany's dominant position in this respect -- deserve a special attention. As it was stated by Pradetto:

"Germany was the microcosm of Europe when the continent was divided. Germany is the microcosm of Europe now the continent is united -- or trying to be united. The experiences with establishing a united social and economic area in the former Germany will be important when trying to rebuild Eastern Europe and to construct a united Europe ${ }^{m 30}$.

In the very same manner, Eastern European governments should force themselves to develop some economic policies. At present there are various suggestions on this point as well ${ }^{34}$. This is not just an issue of meeting the requirements of some suggestions, but beyond that, it is a matter of gaining a cooperative posture towards certain Western European institutions which are in progress since the early 1990's. Credits to Eastern European countries on the basis of certain projects provided by the European Bank of Reconstruction and Development since 1990; the TEMPUS project initiated by the EC Commission in the field of training and the academic cooperation, and the interim agreements that have already been concluded with almost all of these countries with the EC are but some examples of the important developments indicating the willingness and the cooperative tendencies by the $\mathrm{EC}^{32}$. The essence of such tendencies has to be grasped carefully. Therefore, the idea of integration with the EC can turn out to be a realistic security option for Eastern Europe to the extent, a) they can take proper actions to create a positive drive on the part of Western Europeans towards the region, and also b) they can effectively facilitate their regional capabilities to prepare the bases of the regionwide cooperation. Integration with the EC, then, is a two-way process need to be assessed carefully.

Under the prevailing conditions in Europe, this process may not easily be at-

29 August Pradetto, "Transformation in Eastern Europe," p. 23.

30 As it is further stated by the author, "German democratic system is considered to be the foremost in the region because of its administration, constitution, judicial system, and political stability. lbid., p. 28

31 Ibid., p. 26.

32 These interim agreement $s$ could be regarded as the bases of the association agreements in the future provided that the rate of democratization process and the achievemnts towards a market economy structure in the region can meel certain standards coinciding with the EC criteria. The ongoing arguments relating to social unrest and ethical disputes that could result from the rapid transition to market economy are the typical examples of some obstacles standing before the concerned parties at present. 
tached to an imminent objective to be attained with priority: on the contrary, a kind of "gradualism approach" should be the objective for the decade ${ }^{33}$ ahead. In this manner, at least a conscious policy orientation with the long term objectives can be determined.

On the same geographical basis, some security structures that are being debated by specialists for Europe can be taken into consideration through the same logic by the Eastern Europeans. Many variations and combinations of these ideas including a system based on widening NATO to include the East Central European countries, or a system based on widening and strengthening the European Community, with the WEU as its military arm and for a system based on strengthening the CSCE are but a few among the wide range of possibilities at present. A rapid involvement in an integration process in the political direction to cover fundamental security designs may not easily be placed into the category of imminent objectives to be attained in the region. However, a growing understanding in this direction and improving some common concepts on the respective issues of security can definitely contribute to developing a proper psychological ground upon which certain initiatives for the future can be designed.

The Eastern axis is another direction in geographic terms to be considered by Eastern Europe in solving their transformation problem. Regardless of how far the Central European countries may want to move by themselves, to a certain extent they will still remain dependent on trade with the eastern states mainly with Russia. In this respect, as it was stated by Josef M. Van Brabant, "the economic merits, as distinct from current foreign-policy angles, of a Central European Economic Union (CEEU) are fairly obvious ${ }^{\text {334 }}$. Thus, the CEEU should not be seen as an alternative to joining Europe: "quite the contarry: I see it essentially as a temporary stage to facilitate the transition phase, both in terms of time required and the costs incurred in the process, toward the reforming countries eventually becoming fully integrated members of a united Europe, perhaps around the turn of the century ${ }^{\text {m35 }}$.

Starting from the region wide basis and opening towards the East, wide range of potentialities already exist. The Black Sea initiative is one of these. The regional outlook in this respect can easily be extended to China and even Japan. Arguments taking Eastern Europe as an alternative West for China's middle class and prospects

33 Amitai Etzioni; "European Unification: A Strategy of Change," in World Politics, 1963, V. 16, pp. 32-51.

The gradualism approach amplifies close targets and underplays more remote (and more ambitious) ones; it breaks up, into small bits, both the adjustments the parties have to make and the loss of sovereignty they have to endure; it allows "streich outs"; and it follows a multi-path approach.

34 Joseph M. Van Brabant, "Renewal of Cooperation and Economic Transition in Eastern Europe, "in Studies in Comparative Communism, Vol., XXIV, No. 2, June 1991, pp. 151-172 (p. 161).

35 Ibid., p. 163. 
for the region in this respect are among the interesting debates on the subject at present. As it was stated by Richard Kraus, "Eastern European culture has a continuing role in giving shape to the consciousness of Chinese's urban middle class as it offers a socially respectable set of values for China's industrializing elite ${ }^{m 36}$.

More than the validity of these and similar thoughts and related arguments the point here is the necessity for Eastern Europe to process a globally oriented posture in assessing their security concerns. It is of a vital importance for them to develop new perspectives (and to coincide these perspectives with existing ones) both in geographical and functional terms in a manner to prepare the most suitable political environment in which their overall transformation process could proceed to meet their security expectations. The nature and the scope of the integrationist tendencies at present should be studied carefully so that the "time" and "space" factors (two essential dimensions of strategic decisions) could effectively be utilized. It is in this respect that such functional areas as economy and the social orders can be conceived as the "mass-factor" (the third essential dimensions of strategic decisions) to be manipulated in time and space with priority in preparing suitable environments. "Time" has to be manipulated on the basis of "gradualism approach" in combination with globally determined "space concept". It is in this sense that the economic orientations could be regarded as an indirect way of carrying the overall policy objectives of Eastern European countries into international arena. This could be a proper manner of manipulating one area of interest in the fulfillment of the rest.

In our increasingly interdependent world, nearly every change seems to be connected somehow to another. If we can select the principal manners in which global politics are changing, we can begin to suggest how those changes may stimulate or inhibit change in others, less volatile features of world politics. The reality in this respect has to be grasped very carefully through a global perspective both in geographical and functional terms. A sound theoretical base will be an essential asset to begin with; and the success for Eastern Europeans will very much depend on their achievements in coinciding theory with the reality in proper terms.

36 Richard Kraus, "Eastern Europe as an Alternative West China's Middle Class, "in Studies in Comparative Communism, Vol. XXII, No. 4 Winter 1989, pp. 323-336. (p. 336).

According to Kraus, "the middle-class culture accomplishes many things: it entertains, inspires, and it provides a repository of tips about proper middle-class behavior. In all these, Eastern Europe has been a safer source of bourgeois lessons than the capitalist West." 